\title{
Discrete Dynamics in Transitional Economies
}

\author{
J. BARKLEY ROSSER, JR.* and MARINA VCHERASHNAYA ROSSER \\ Program in Economics, College of Business, James Madison University, Harrisonburg, VA 22807, USA
}

(Received in final form 23 June 1997)

\begin{abstract}
This paper traces the transition from planned command socialism to market capitalism and the accompanying complex non-linear dynamics involved. Long wave chaotic hysteretic investment cycles emerge under socialism leading to crisis and breakdown. Macroeconomic collapse occurs with bifurcations of coordination structures during transition. During recovery, transitional cobweb labor market dynamics exhibit chaos, fractal basin boundaries between coexisting non-chaotic attractors, discontinuous phase transitions, strange attractors, and cascades of infinitely many period-doubling bifurcations.
\end{abstract}

Keywords: Socialism, Transition, Chaos, IPS, Cobweb

\section{INTRODUCTION}

The process of systemic economic transformation from planned command socialism to market capitalism has proven to be unpredictable and highly complicated with a variety of divergent paths and outcomes emerging from the breakup and collapse of the former Soviet-led CMEA bloc. ${ }^{1}$ Although social, political, and cultural factors played important roles in the actual collapse, an underlying factor and portent was the long economic stagnation that had become increasingly pronounced and which eventually led to a crisis atmosphere, especially in the USSR. This led to the reform efforts that would lead to actual eco- nomic decline and the breakup of the bloc and the broader collapse of the system.

The reform efforts, which spread in various ways and at various rates to the various countries in the bloc, and had already been going on for some time in China without any decline in economic activity, led to extremely sharp declines in economic activity among the CMEA members as the bloc broke up and in the aftermath of the breakup. This was the period of the most intense systemic transition when old economic institutions disintegrated and the effort began to install new ones in their place. In many countries this effort is still continuing and this stage of economic decline has not yet ended.

\footnotetext{
*Corresponding author. Tel.: 540-568-3212. Fax: 540-568-3010. E-mail: rosserjb@jmu.edu.

${ }^{1}$ For an overview of alternative paths among the transitional economies, see Rosser and Rosser (1996a), Murrell (1996), Fischer et al. (1996), and de Melo and Gelb (1996).
} 
However, in others a turnaround has occurred and growth has resumed, albeit not always in an orderly or fully stable manner. This process of sharp decline followed by an upturn has been labeled the "J-curve" effect (Brada and King, 1992). A few countries, most notably Poland and the Czech Republic, have recovered to the point that their per capita incomes have surpassed their pre-collapse levels. However, with a few exceptions, ${ }^{2}$ most of these nations have experienced political and social upheavals during this process. In some cases this has led to sharp changes in economic policies with extreme instabilities and accompanying oscillations resulting therefrom. In all cases, even in the arguably highly successful case of China, the process of transition has been marked by notable discontinuities and turbulence of many kinds.

In this paper we seek to explicate to some degree the varieties of these episodes of discontinuity and turbulence by using some of the tools available in complex non-linear dynamics. We shall model both discontinuous changes as well as chaotic and other kinds of complex dynamics occurring during the course of these transitional processes. These will be hypothetical theoretical models which we find suggestive for explicating some of the phenomena that have been and are being observed within these economies. We shall not use any econometrics to test these conditional hypotheses. One reason for this is the shortness of the time period involved and thus the paucity of data compared to what is required to use the appropriate methods (Brock et al., 1991). Nevertheless, an original aspect of this paper is its effort to theoretically model within the complex non-linear dynamics framework the entire process of transition from the emergence of crisis within the old command planned socialist economy through the collapse to the recovery and regeneration phase.
Section II of the paper examines the first stage, drawing on a version of the Bauer (1978) model of investment fluctuations in a centrally planned economy as developed by Rosser and Rosser (1994; 1995; 1997a) from a model of Puu (1990; 1997) to consider the development of the systemic crisis. Section III will examine the phenomenon of discontinuous collapse during the second phase as an example of coordination failure arising from institutional disintegration, drawing on models of Brock (1993) and Aghion and Blanchard (1994) as modified by Rosser and Rosser (1996b; 1997b). Section IV carries the analysis forward to transitional dynamics within recovering economies where policy instabilities are associated with further complexities of dynamics, drawing on the previous models and work of Brock and Hommes (1997) as modified by Rosser and Rosser (1996c). From these models a taxonomy of various transition paths can be discerned, hopefully with some connection to real events as discussed in the concluding section.

\section{THE CRISIS OF THE COMMAND SOCIALIST SYSTEM}

From a strictly economic perspective, two aspects stand out in the long process of deepening stagnation in the Soviet-style, centrally planned, command socialist economies. One was that of technological stagnation and the other was the closely related long term decline in the marginal productivity of capital investment that manifested itself in a secular increase in the capitaloutput ratios in these economies. Shorter term cycles of investment culminated in a longer term decline of decreasingly productive investment that precipitated the crisis of the system.

A major virtue of the centrally planned command economies was their ability to stabilize

\footnotetext{
${ }^{2}$ It is unsurprising that the former CMEA member that has experienced the smoothest economic transition, the Czech Republic, has also experienced the least political upheaval, although it has been experiencing financial upheavals since late 1996 that have begun to have political ramifications.
} 
macroeconomic output. However, the growth of investment could fluctuate cyclically, usually in tandem with five-year planning cycles (Kalecki, 1970; Goldmann, 1975). Bauer (1978) saw this as arising from bureaucratically driven "investment hunger" in four stages: a "run-up" when many investment projects are started, a "rush" when investment activity accelerates, a "halt" when the approval of new projects declines as internal or external constraints are encountered, and a "slowdown" when investment may actually decline as previously started projects are completed. Simonovits (1991a,b) showed a variety of cyclical dynamics as possible from a formalization of this model and Hommes et al. (1995) extended this to show the possibility of chaotic dynamics for this model.

Rather than follow directly the models of short-term planning-induced investment fluctuations noted above, we are more interested in the longer term evolution of this process, a process of long waves of capital investment that can be identified with larger-scale infrastructure investments and investments related to broad Schumpeterian technique clusters (Rosser, 1991, Chap. 8; Rosser and Rosser, 1997a). ${ }^{3}$ These fluctuations remain disconnected from output fluctuations, the rate of growth of output gradually decelerating with technological stagnation and declining capital-output ratios. Our model (Rosser and Rosser, 1994; 1995) of these fluctuations is a modification of a model of Puu $(1990 ; 1997)$ of the non-linear multiplieraccelerator model, originally due to Hicks (1950) and Goodwin (1951), but reinterpreted as a long wave capital self-ordering model with a secondstage accelerator associated with investment in the investment sector itself (Forrester, 1977; Sterman, 1985; Sterman and Mosekilde, 1996).

Let investment be allocated between the consumption and investment sectors, with IC being investment in the consumption sector and II being investment in the investment sector. Then

$$
I_{t}=\mathrm{IC}_{t}+\mathrm{II}_{t}
$$

Investment in the consumption sector is given by a relationship that resembles the traditional consumption multiplier in the usual multiplieraccelerator model of output, being

$$
\mathrm{IC}_{t}=(1-v) I_{t-1} .
$$

Investment in the investment goods sector is given by a relationship that resembles the accelerator part of a non-linear multiplier-accelerator model of output, but with a cubic formulation proposed by Puu $(1990 ; 1997)$, justified by him on the basis of countercyclical government investment policies. ${ }^{4}$ This is given by

$$
\mathrm{II}_{t}=u\left(I_{t-1}-I_{t-2}\right)-u\left(I_{t-1}-I_{t-2}\right)^{3} .
$$

If we let $z_{t}=I_{t}-I_{t-1}$, then the model reduces to

$$
I_{t}=I_{t-1}+z_{t}
$$

and

$$
z_{t}=u\left(z_{t-1}-z_{t-1}\right)^{3}-v I_{t-1} .
$$

The behavior of $I$ as a function of $z$ can now be examined according to variations of the parameters, $v$ and $u$. Puu $(1990 ; 1997)$ has done so for an equivalent model of output and finds that as $v$ approaches zero, the amplitude and period of the cycle lengthen and can take on a long wave interpretation. As $u$ increases from 1.5 to 2, period-doubling bifurcations occur with chaotic dynamics emerging for $u \geq 2$ within the larger cycle. For $u \geq 2$, as $v$ increases, the period and

\footnotetext{
${ }^{3}$ Closely related to the concept of a technique cluster is that of a "techno-infrastructure" (Day and Walter, 1989). It is possible to view the systemic collapse as a decline from one such techno-infrastructure, or technique cluster, to a lower one, although this can easily be questioned.

${ }^{4}$ In the original formulations of Hicks (1950) and Goodwin (1951) there were simply floors and ceilings to investment, rather than the "backward bends" implied by a cubic formulation. Samuelson (1939) had earlier posed the possibility of non-linearity in his multiplier-accelerator model, but posited it as arising from the consumption function rather than the investment accelerator.
} 
amplitude of the long wave cycle decline and the chaotic dynamics come to fully dominate.

Figure 1, drawn from Puu $(1990$; 1997) represents an intermediate case, with $v$ very small and $u=2$. Thus there is a long wave oscillation with chaotic dynamics occurring within the cycle at the jumps from one branch to another. We note that the chaotic dynamics appear after the jumps and that there then follow period-halving bifurcations as the system transits out of chaotic dynamics to simple behavior. Such a pattern of jumps between distinct branches with chaos occurring with the jumps can be called "chaotic hysteresis" (Rosser, 1991, Chap. 17; Rosser and Rosser, 1995).

In the Sterman-Mosekilde (1996) capital selfordering model, such a system generates a 49 -year

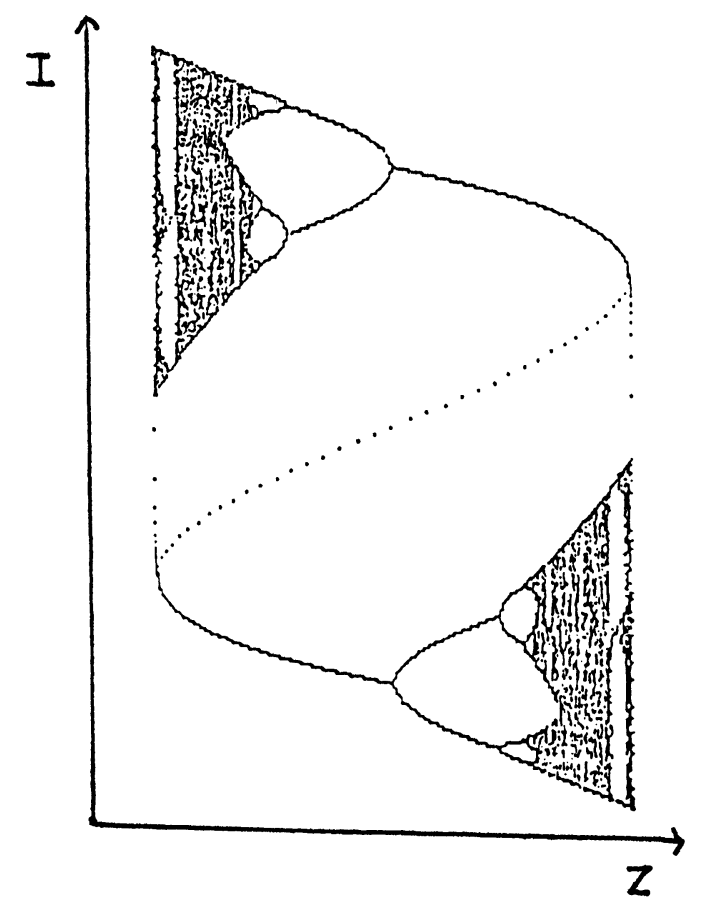

FIGURE 1 Chaotically hysteretic socialist investment cycles. endogenous cycle of output. Such an outcome for a long wave investment cycle is easily conceivable within our framework above. In Rosser and Rosser $(1995 ; 1997 a)$ data on Soviet investment and construction is presented that is argued to be consistent with this model which was originally presented in Rosser and Rosser (1994). A turbulent period occurred in the late 1940s and early 1950s, followed by short-term fluctuations within a larger cycle that eventually culminated in a deceleration and collapse of investment in the late 1980s and early 1990s. We suggested that this represented a crisis of the system within its pattern of investment within an older technique cluster that had become obsolete by global standards. The recognition of this lag played a significant role in triggering the political-economic changes that immediately led to the collapse of the whole system.

\section{THE DYNAMICS OF OUTPUT COLLAPSE DURING TRANSITION}

Perhaps the most dramatic economic aspect of the transition process has been the very sharp declines in output occurring in virtually all of the former CMEA nations, declines predicted by few economists, most of whom had been fairly optimistic about their future prospects based on the historical experience in West Germany of the Wirtschaftswunder after 1948. In retrospect it is now clear that there were at least two reasons why the FRG's experience was not recapitulated in the post-CMEA economies. One was the sharp initial shock to exports in all these states as the CMEA itself was dissolved and these economies were opened to competition with the market capitalist economies. ${ }^{5}$ The second, less expected and harder to model, was the impact of the collapse of institutions, ${ }^{6}$ the changes required

\footnotetext{
${ }^{5}$ For discussion of trade patterns and reform policies in the former Soviet Union, see Rosser (1993a,b).

${ }^{6}$ Among those emphasizing the role of institutional collapse on information transmission and the formation of appropriate incentive structures within the nascent market economies include Murrell (1991), Ellman (1994), Kornai (1994), Stiglitz (1994), and Yavlinsky and Braguinsky (1994). Those emphasizing the role of the non-functioning of credit institutions include Calvo and Corricelli (1992), Uhlig (1993), and Melitz and Waysand (1994).
} 
to become market capitalist economies being much larger than for the case of already capitalist West Germany in 1948. This is emphasized by noting that China's economy has not collapsed and avoided both a shock to exports as it opened with the Dengist reforms and avoided an institutional collapse as it gradually allowed market and capitalist institutions to emerge within the interstices of the previously existing system.

Here we follow Rosser and Rosser (1996b; 1997b) in modeling the decline of output after the initial shock to exports as a problem of coordination failure. This takes place within a transitional labor market model due to Aghion and Blanchard (1994). Coordination failure arises from a phase transition within an interacting particle systems (IPS) model adapted from Brock (1993) arising from the degree of interaction between agents and the strength of their attitudes. ${ }^{7}$

Following Aghion and Blanchard (1994), let the total labor force equal 1, with that in the state sector equaling $E$, which is initially equal to 1 also. That employed in the private sector equals $N$ and the number unemployed equals $U$. After an initial shock, presumed due to the sudden decline of exports, $E<1$ and $U>1$. The marginal product of state workers is $x<y$ which is the marginal product of private sector workers. Taxes in both sectors per worker equal $z$ which pays for benefits per unemployed worker equal to $b$.

Letting $w$ equal private sector wages, state sector workers capture quasi-rents equal to $q>1$ with their wages determined by

$$
w(E)=q x-z .
$$

State sector layoffs equal $s$, a policy variable, and we assume that there is no rehiring in that sector.

Private sector job formation is given by

$$
\mathrm{d} N / \mathrm{d} t=a(y-z-w),
$$

with the value of $a$ being a function of the institutional framework of the economy and its re- sulting ability to coordinate signals, along with legal, property, financial, and regulatory institutions. Let $H$ equal the number of private sector hires coming strictly from the unemployed, $r$ be the interest rate, $c$ be a constant difference between the "value of being (privately) employed," $V(N)$, and the "value of being unemployed," $V(U)$, this latter determined by an efficiency wage outcome. This gives private sector wages as

$$
w=b+c[r+(H / U)],
$$

with the values of $V(N)$ and $V(U)$ given by arbitrage equations:

$$
\begin{aligned}
& V(N)=[w+\mathrm{d} V(N) / \mathrm{d} t] / r, \\
& V(U)=[b+c(H / U)+\mathrm{d} V(U) / \mathrm{d} t] / r .
\end{aligned}
$$

Total unemployment benefits, $U b$, are given by

$$
U b=(1-U) z .
$$

The above imply a reduced form of private sector job formation given by

$$
\begin{aligned}
\mathrm{d} N / \mathrm{d} t & =a[U /(U+c a)]\{y-r c-[1 /(1-U)] b\} \\
& =f(U) .
\end{aligned}
$$

The dynamics of this represented by this equation are depicted in Fig. 2 and depict conflicting impacts of unemployment upon private sector job formation. The first term in Eq. (12) reflects that downward wage pressure tends to stimulate job formation while the second term reflects that rising unemployment benefits raise taxes thereby depressing job formation. In Fig. $2, U^{*}$ is the level of unemployment beyond which the depressive second term begins to outweigh the stimulative first term. In this figure we also see a level of $s$ that implies two equilibria with $\mathrm{U} 1$ being stable and $\mathrm{U} 2$ unstable. If $U>\mathrm{U} 2$, the economy implodes to a condition of no private sector job formation.

\footnotetext{
${ }^{7}$ Alternative approaches to coordination failure are discussed in Guesnerie (1993) and Colander (1996).
} 


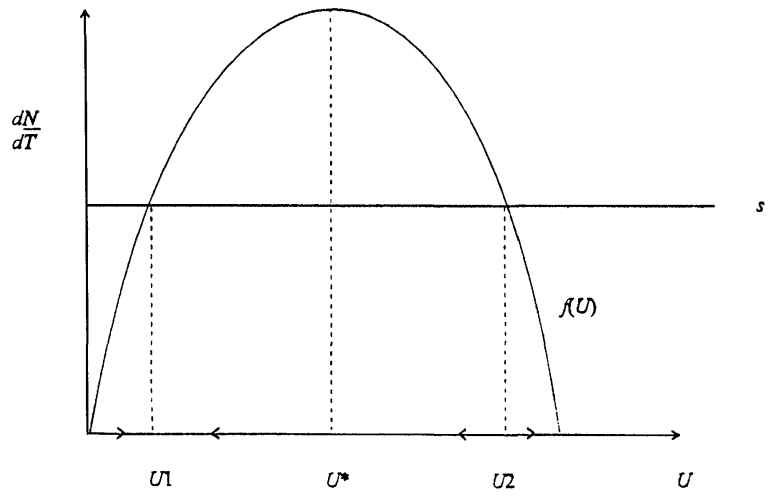

FIGURE 2 Transitional economy employment functions.

The height of $f(U)$ in Fig. 2 depends on the value of $a$. Thus, a discontinuous change in $a$ could cause a discontinuous shift in $f(U)$. Most particularly, a discontinuous decline in $a$ due to an institutional collapse could shift $f(U)$ to an $f\left(U^{\prime}\right)$ below the level of $s$. This could cause a destabilization of the formerly stable and low unemployment level of $\mathrm{U} 1$ and the implosion of the economy to the no-private-job-formation equilibrium. Such a scenario is depicted in Fig. 3.

Let us now consider the dynamics of such a sudden decline in the value of $a$, following the IPS model approach due to Brock (1993) as derived ultimately from Kac (1968). Let there be $F$ firms in the private sector, ${ }^{8}$ existing within a fully specified web of mutual buyer-seller relations and production externality relations. Hiring by firms depends partly on discretely chosen attitudes from a possible set, $K$, each firm $i$ having positive (optimistic) or negative (pessimistic) $k_{i}$. The strength of these $k$ 's depends on a continuous function, $h$, applying to all firms and varying over time, with their average equaling $m . J$ is the average degree of interaction between firms, which can be viewed as a proxy for the degree of signal coordination or information transmission. ${ }^{9} \beta$ indicates "intensity of choice," a measure of how

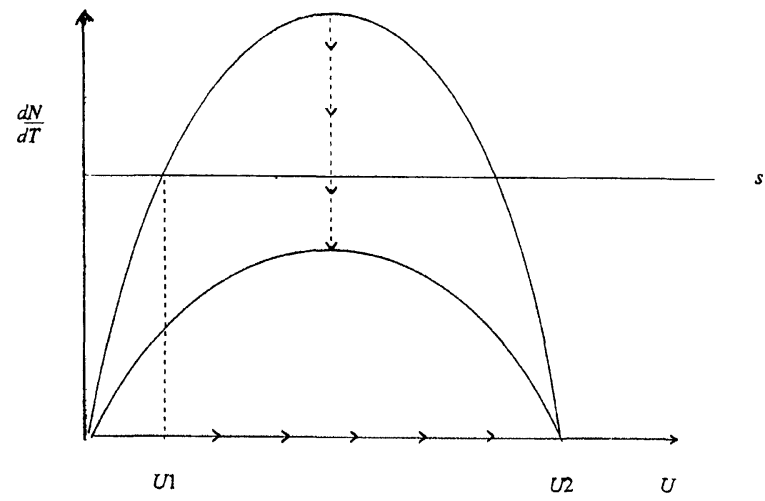

FIGURE 3 Employment collapse in economic transition.

much firms are either optimistic or pessimistic, with $\beta=0$ indicating random outcomes over the choice set. ${ }^{10}$ Choices are $\epsilon\left(k_{i}\right)$, stochastically distributed independently and identically extreme value.

Assuming that direct net profitability per firm of hiring a worker is given by $(y-z-w)$, not accounting for interfirm externalities, then the net addition of jobs per firm is

$$
\begin{aligned}
(\mathrm{d} N / \mathrm{d} t) / F= & (y-z-w)+J m k_{i} \\
& +h k_{i}+(1 / \beta) \epsilon\left(k_{i}\right) .
\end{aligned}
$$

Substituting from Eq. (7) allows to solve for $a$ as

$$
a=1+F\left\{\left[J m k_{i}+h k_{i}+(1 / \beta) \epsilon\left(k_{i}\right)\right] /(y-z-w)\right\} .
$$

If there is an equal rate of interaction between firms, then $m$ characterizes the set of $k$ 's and if the choice set is restricted to $(+1,-1)$, then Brock (1993, pp. 22-23) shows that:

$$
m=\tanh (\beta J m+\beta h)
$$

where tanh is the hyperbolic tangent. $\beta J$ is a bifurcation parameter with a critical value equal to 1 ,

\footnotetext{
${ }^{8} \mathrm{~F}$ is assumed to be constant, possible if we allow "potential" firms to have zero output.

${ }^{9}$ See Guesnerie (1993) and Colander (1996) for more general discussions of the role of signal coordination.

${ }^{10}$ In the original IPS literature $\beta$ is "temperature" (Kac, 1968), with critical values being associated with phase transitions in material states, such as melting or boiling.
} 
as depicted in Fig. 4. If $\beta J<1$ there is a single solution with the same sign as $h$. For $\beta J \geq 1$ there are two discrete solutions, with $m(-)=-m(+)$. Thus a continuous change in either or both $\beta$ or $J$ or both could trigger a discontinuous change in $a$, and if this were a decline, the scenario depicted in Fig. 3 of a macroeconomic collapse.

There is more than one possible scenario here within this story. Thus, it could be argued for some cases that the command planned system was in the upper right branch of Fig. 4 initially, reflecting a high degree of coordination within the system. As the degree of coordination declined with the end of planning the system moved to the branch to the left. Or alternatively it could be argued that it began on that branch, and then moved to the right with an increase in the intensity of choice of emerging private firms, but in the face of a lack of institutional support they become pessimistic and drop to the lower right branch in Fig. 4. Yet a third scenario could be that just described but where the firms become optimistic and jump to the upper right branch. This scenario, implying a discontinuous upward leap in the growth rate, might explain the Chinese case. ${ }^{11}$

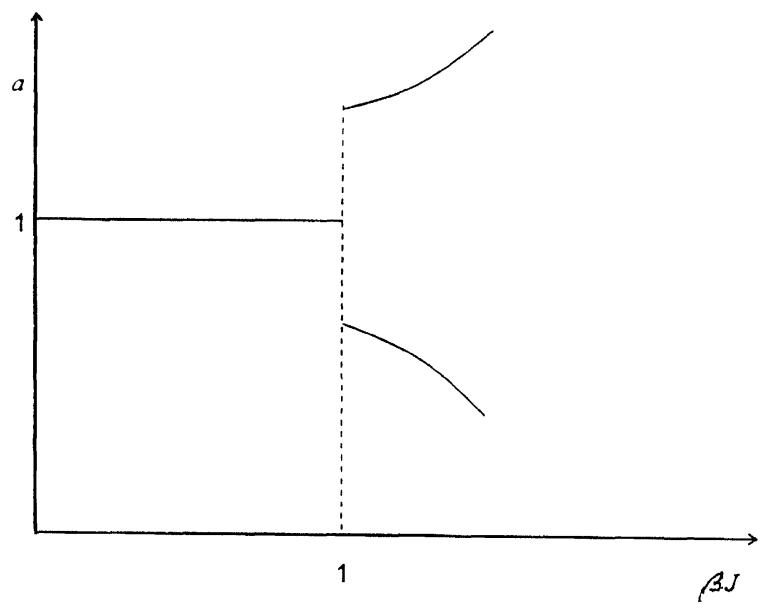

FIGURE 4 Bifurcation in IPS model.

\section{TRANSITIONAL UPSWING COMPLEXITIES}

An increasing number of transitional economies appear to be getting beyond the kinds of collapse scenarios depicted in the previous section and are experiencing growth in conjunction with a process of privatization or restructuring of suddenly privatized firms, as the new institutional framework takes shape. Nevertheless, this process has seen numerous political backlashes as the numerous losers in the process react against what is happening. ${ }^{12}$ The upshot has been considerable political instability and churning in many countries, including some such as Poland that have been among the most successful according to standard growth statistics, and even in the most successful of all such economies, China (Zou, 1991).

Following Rosser and Rosser (1996c), we shall continue our focus upon labor market dynamics within a modified version of the model considered in the previous section. We shall use a difference equation rather than differential equation approach and given that we are considering a growth transitional scenario will dispense with considering the impact of unemployment benefits and the associated taxes. We shall normalize by setting state sector wages at zero and assume that private sector wages are strictly positive. Furthermore we shall now endogenize $s$, the rate of state sector layoffs as a positive function of the difference between the private and state sector wages, with $s=0$ if the two are equal, which could be viewed as occurring at an endpoint of the transition process beyond the purview of this paper.

Thus the basic equation for private sector job formation reduces to

$$
N_{t}-N_{t-1}=a\left(y-w_{t}\right),
$$

\footnotetext{
${ }^{11}$ Such a contrast between self-fulfilling optimistic and pessimistic scenarios within privatizing transition economies has been studied using game theory by Laban and Wolf (1994).

${ }^{12}$ One prominent phenomenon in many of the growing transitional economies that has proven very disruptive has been the widespread outbreak of speculative bubbles that then collapse in many of the nascent financial markets (Tamborski, 1995).
} 
with the rate of state sector layoffs given by

$$
s_{t}=k w_{t} .
$$

Equality of (16) and (17) constitutes an equilibrium transition path, which need not be unique and could coincide with any level of unemployment. If this de facto state labor supply function operates with a one-period lag then this system will behave like a cobweb model whose dynamics will be determined by whether $k / a$ is less than, equal to, or greater than unity, with the first case being stable, the second harmonic, and the third unstable (Ezekiel, 1938). ${ }^{13}$ This model will differ from a more standard labor market model in that the quantity axis will be in rates of change rather than in levels. ${ }^{14}$

We adopt the approach of Brock and Hommes (1997) in assuming that the decision maker, the state in this case, uses a combination of two predictors of the private sector wage in making its layoff decisions. $\mathrm{H} 1$ is a perfect predictor but has information costs, $C>0 . \mathrm{H} 2$ is a static predictor that is free. ${ }^{15}$ The proportion of $\mathrm{H} 1$ entering into the state's prediction in time $t$ will be $n_{1, t}$ and the proportion of $\mathrm{H} 2$ will be $n_{2, t}$. Drawing on a vector of past wages, $W t$, the state will switch between these predictors, based on an intensity of choice parameter, $B$, and upon the most recent squared prediction errors of the respective predictors.

Equilibrium path dynamics will be given by

$$
N_{t+1}-N_{t}=n_{1, t} k(\mathrm{H} 1(W t))+n_{2, t} k(\mathrm{H} 2(W t)) .
$$

Switching based on most recent squared prediction error will give the respective shares of the predictors as

$$
\begin{aligned}
& n_{1, t+1}=\exp \left\{-B\left[\left(w_{t+1}-\mathrm{H} 1(W t)\right)^{2}+C\right]\right\} / Z, \\
& n_{2, t+1}=\exp \left\{-B\left[w_{t+1}-\mathrm{H} 2(W t)\right]^{2}\right\} / Z,
\end{aligned}
$$

where $Z$ is the sum of the numerators. Letting $m_{t+1}=n_{1, t+1}-n_{2, t+1}$ implies that if only $\mathrm{H} 1$ is being used then $m_{t+1}=1$ and it will equal -1 if only $\mathrm{H} 2$ is being used:

$$
\begin{aligned}
m_{t+1}= & \tanh (B / 2)[\mathrm{H} 1(W t)-\mathrm{H} 2(W t) \\
& \left.\times\left(2 w_{t+1}-\mathrm{H} 1(W t)-\mathrm{H} 2(W t)-C\right)\right] .
\end{aligned}
$$

Brock and Hommes (1997) call the combination of (18) and (21) an adaptive rational equilibrium dynamic trajectory, or ARED.

Our assumption that $\mathrm{H} 1$ is a perfect but costly predictor while $\mathrm{H} 2$ is a free static predictor can be given by

$$
\begin{aligned}
& \mathrm{H} 1(W t)=w_{t+1}, \\
& \mathrm{H} 2(W t)=w_{t} .
\end{aligned}
$$

Using this along with a simplifying assumption that $y=0$ so that $w$ can be viewed as a deviation from a long-run steady state provides an equilibrium solution for $w$ as

$$
\begin{aligned}
w_{t+1}^{*} & =\left[-k\left(1-m_{t}\right) w_{t}\right] /\left[2 a+k\left(1+m_{t}\right)\right] \\
& =f\left(w_{t}, m_{t}\right) .
\end{aligned}
$$

ARED is given by Eq. (24) and

$$
\begin{aligned}
m_{t+1}= & \tanh \left\{( B / 2 ) \left[\left(k\left(1-m_{t}\right)\right.\right.\right. \\
& \left.\left.\left./\left(2 a+k\left(1+m_{t}\right)\right)+1\right)^{2} w_{t}^{2}-C\right]\right\} \\
= & g\left(w_{t}, m_{t}\right),
\end{aligned}
$$

\footnotetext{
${ }^{13}$ Chiarella (1988) shows that even monotonic supply and demand curve models can behave chaotically if there are sufficiently long lags. See Hommes $(1991 ; 1994)$ for further discussion of chaotic cobweb models.

${ }^{14}$ Peter Flaschel has noted to us that this means that this is essentially a disequilibrium or temporary equilibrium model. We emphasize that this formulation is only relevant during a transition process and that a more standard equilibrium formulation becomes more relevant once the transition ends.

${ }^{15}$ A similar approach of conflicting predictors leading to complex dynamics can be found in Grandmont (1994), Sorger (1994), and Palmer et al. (1994). Such systems can underlie "chaotic bubbles" as seen in Day and Huang (1990).
} 
which possesses a unique steady state at

$$
S=\left(w^{*}, m^{*}\right)=(0, \tanh (-B C / 2))
$$

If $C=0$ then $\mathrm{H} 1$ always dominates and the steady state will be stable at $(0,0)$. If $C>0$ there will exist a $B^{*}$ at which period-doubling bifurcation will occur with the two period cycle given by

$$
\begin{aligned}
(\hat{w,}, \hat{\imath}) & =\left(-\hat{w}, m^{\wedge}\right), \\
m^{\wedge} & =-a / k,
\end{aligned}
$$

with $w^{\wedge}$ given by the unique solution to

$$
\tanh [B / 2(4 \hat{w}-C)]=-a / k .
$$

In the unstable cobweb case where $k / a>1$, when the system bifurcates again, two coexisting four period cycles emerge. Brock and Hommes (1997) show that as $B$ increases from 1.36 to 1.37 the basin boundary between these coexisting attractors appears to become fractal, implying erratic dynamics even without any appearance of other forms of complex dynamics. ${ }^{16}$ The ARED given by (24) and (25) can be qualitatively analyzed by examining $L(B)$ which is $[f(w, m)$, $g(w, m)]$ as a function of $B$. For the steady state, $L(B)$ will have a stable manifold, $\operatorname{Ms}\left(w^{*}, m^{*}\right)$ and an unstable manifold, $\mathrm{Mu}\left(w^{*}, m^{*}\right)$, which are depicted in Figs. 5(a) and (b) for a sufficiently high $B$. Figure 5(a) holds for

$$
1<k / a<(1+\sqrt{5}) / 2
$$

while Fig. 5(b) holds for

$$
k / a>(1+\sqrt{5}) / 2
$$

In both cases the stable manifold is the vertical line segment at $w=0$ and the horizontal line segments at $m=1$ and $m=-1$, while the symmetric curves emanating from $(0,-1)$ constitute the unstable manifold.
Brock and Hommes (1997) demonstrate that as $B$ increases these manifolds approach having homoclinic intersections which generates a variety of complex dynamics. More formally they (op. cit., Appendices 4.2 and 5.2) show:

Proposition 1 For any $C>0, k / a>1$, and any $\varepsilon>0$, there will exist a $B^{* *}$ such that, for all $B>B^{* *}$, $\mathrm{Mu}\left(w^{*}, m^{*}\right)$ will be within an $\varepsilon$ neighborhood of both the horizontal and vertical segments of $\mathrm{Ms}\left(w^{*}, m^{*}\right)$ as depicted in Figs. 5(a) and (b) according to the conditions stated in Eqs. (30) and (31).

Although the unstable manifold becomes arbitrarily close to the stable segment $w=0$ as $B$ increases, no transversal homoclinic intersection occurs because for $m<1, w$ changes sign each succeeding period thereby preventing a jump onto the $w=0$ segment. Such a transversal homoclinic intersection between stable and unstable manifolds would be sufficient for the existence of a full horseshoe with an invariant Cantor set near the homoclinic orbit that contains infinitely many periodic orbits and an uncountable set of chaotic orbits, indeed an infinite set of such horseshoes (Smale, 1965; 1967).

Palis and Takens (1993, Appendix 5) show that if the steady state stable and unstable manifolds possess a homoclinic tangency, then as they become arbitrarily close transversal homoclinic intersections can occur between the stable and unstable manifolds of periodic saddle points, thereby allowing for the existence of horseshoes and their associated complex dynamics. Such a transversal homoclinic intersection can be shown to occur in this model when there are four-period saddle points, the case mentioned above where coexisting attractors are separated by fractal basin boundaries. $^{17}$

Also, Brock and Hommes (1997) show that one can place a rectangle over certain zones of the unstable manifold in which there is a mapping over

\footnotetext{
${ }^{16}$ See McDonald et al. (1985) for a discussion of such phenomena. Lorenz (1992; 1993) has shown such cases for Kaldor-style business cycle models. See Feldpausch (1997) for further discussion and applications.

${ }^{17}$ We thank William Brock and Cars Hommes for personally communicating this result to us.
} 
(a)

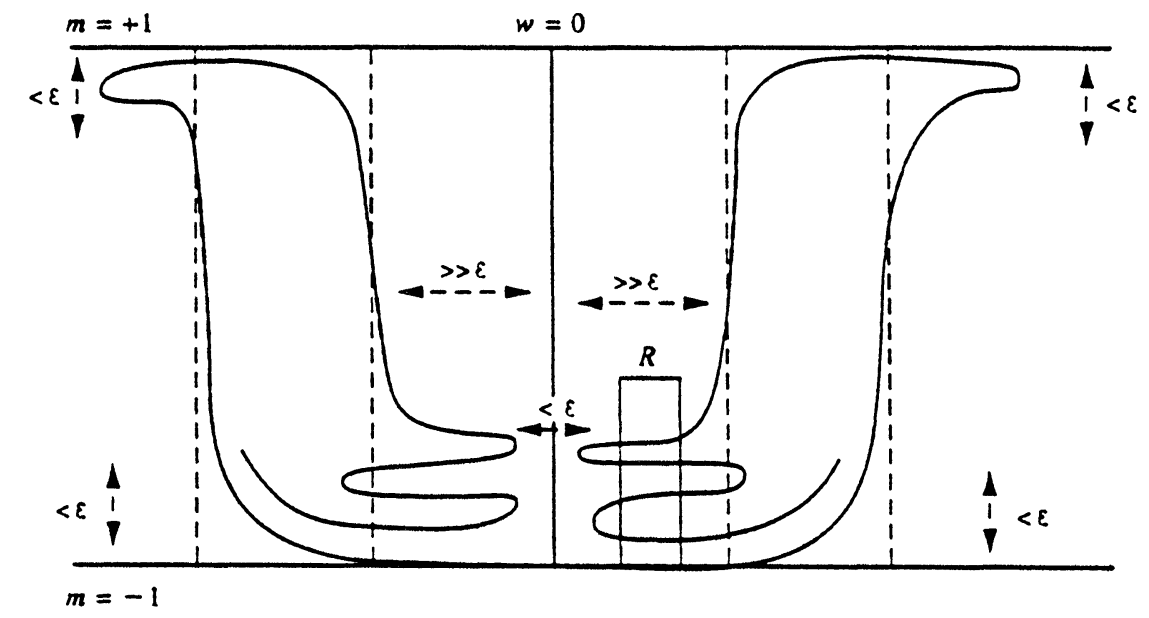

(b)

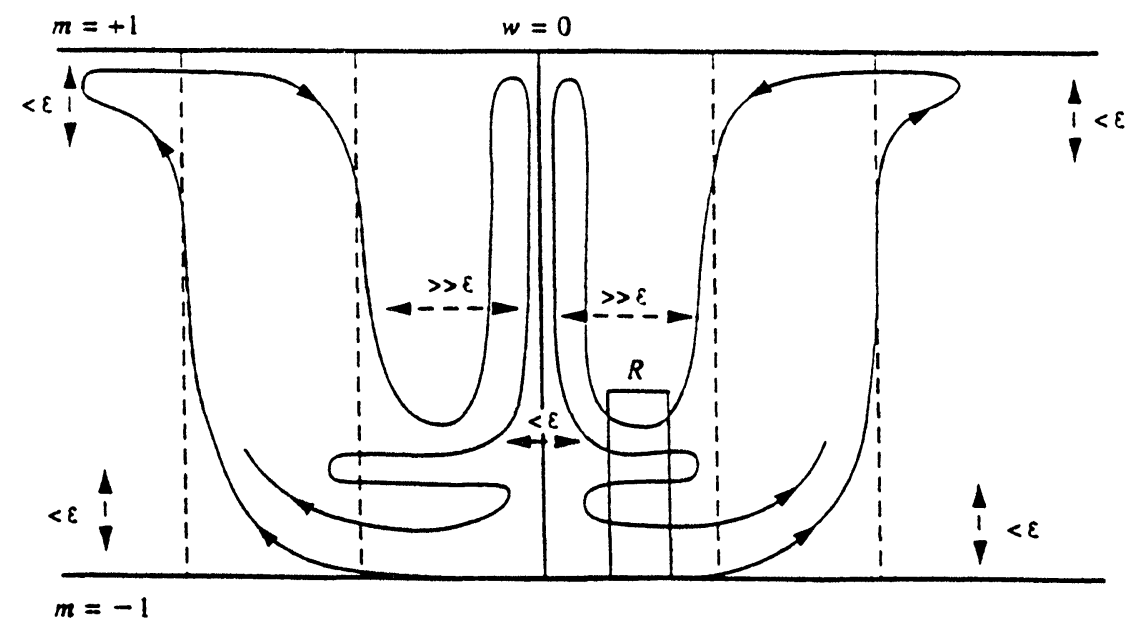

FIGURE 5 Cobweb-induced stable and unstable manifolds with horseshoes.

itself in the form of a horseshoe after a number of periods. This self-accumulation of the manifolds leads to homoclinic tangles with associated complex dynamics including chaotic strange attractors. More formally they (op. cit., Appendices 4.3 and 5.3) show the following proposition.

Proposition 2 If $C>0$ and $k / a>1$ then there exist $B^{\wedge}$ and $N>0$ such that for all $B>B^{\wedge}$ the map $L(B, N)$ has a full horseshoe.
Palis and Takens (1993, Appendix 5) show as a corollary of Proposition 2 that, for generic curves in our quasi-cobweb model with rational versus static expectations, the ARED as $B$ increases will exhibit a positive Lebesgue measure set of $B$ 's for which there will exist Hénon-like attractors (Benedicks and Carleson, 1991; Mora and Viana, 1993), the coexistence of infinitely many stable cycles for a residual set of $B$ 's (the "Newhouse phenomenon") (Newhouse, 1974), and 
cascades of infinitely many period doubling bifurcations (Yorke and Alligood, 1983). Thus, in addition to the possibility of fractal basin boundaries, a variety of other patterns of complex dynamics can arise from this system.

We make no claim that the rather restrictive assumptions required for the full array of these complexities to emerge hold for any actual transitional economy. Nevertheless, the idea that state policy makers operating in the confusing and turbulent circumstances of systemic transition may face a conflict between a stabilizing but expensive predictor and a destabilizing but cheap predictor is not unreasonable. That such a conflict could lead to oscillations of policy in such a situation is not at all unreasonable and may be a useful metaphor for the kinds of policy oscillations and turbulence that we have observed even in transitional economies that appear to have achieved an upswing.

\section{CONCLUSIONS}

There is a strong tendency among many analysts of economic systemic transition to posit a unilinear process from planned command socialism to laissez-faire market capitalism, especially among policy makers at some of the international financial institutions. Countries are grouped into categories according to a "liberalization index" which is then posited to explain most important aspects of the economies in question (de Melo and Gelb, 1996). The usual lesson of such exercises is that "big bang" liberalization is to be encouraged among the wary. The relatively good condition of some countries that rank high on this index, such as Poland and the Czech Republic, is considered to be the proof of the argument.

However, one argument of this paper is that the transition process is a complex one in many ways with numerous potential pitfalls lying along this path. Maintaining some kind of stability during this difficult dynamic may be more important than achieving some high score on some artificially constructed index. Thus, both Poland and the Czech Republic have held back on certain important aspects in order to maintain some stability, the latter more successfully in this regard than the former. This holding back has brought criticism upon them from the international bureaucrats, yet their widely proclaimed success may well have depended upon it. Thus, Poland has been slow to privatize major stateowned enterprises, many of which have been surprisingly successful in international trade (Kamiński et al., 1993), and the Czech Republic has kept effective control of voucher-privatized firms in the hands of still state-owned banks which have followed "soft budget constraint" policies to avoid layoffs (Portes, 1994). And the arguably most successful of all transitional economies, the world's most rapidly growing one of China, has been notable for the gradualism of its approach which has not put it at the far end of the liberalization index.

Indeed, what is more striking is the considerable diversity of outcomes and paths that we can observe. Certainly there was much diversity before the process began, with China differing in many ways from the European CMEA nations, and them varying from more strongly centrally controlled economies such as the Czech Republic to relatively market-oriented Hungary. But the observable differences between the economic performances among these nations far outweigh any other inter-country variations in recent years, from the Chinese supergrowth to nations with sharply declining output, with inflation rates ranging from single digits to the thousands of percents per year (Fischer et al., 1996), from nations such as Hungary and the Czech Republic whose income distributions remain the most equal in Europe to Russia whose income distribution has become the most unequal in the industrialized world (Gottschalk and Smeeding, 1997).

This paper has sought to provide some reasons why we might observe such sharply divergent outcomes from a broadly similar process of transition. We see how, beneath of surface calm of 
macroeconomic stability, a deeper crisis built up in the capital goods sector of the planned command socialist economies as a pattern of chaotic hysteresis. With the ending of the former system and the ending of its institutional framework in the context of a collapse of international trade, we see that these economies faced sharply divergent scenarios of transition depending on signal coordination and the decision making of newly forming firms that could lead to successful and even rapid growth or to deep implosion and depression as critical phase transitions are passed. Finally, we see that even in the case of a growing transitional economy policy oscillations can occur that can take on a variety of highly complex patterns.

All of this suggests that a degree of caution is in order for presumptuously prescribing international authorities. Those nations that have desperately attempted to avoid any changes in the circumstance of a collapsed international system have experienced severe economic difficulties. But, it is also clear that in the face of extreme political and economic instability and turbulence, a healthy concern for maintaining certain stabilizing elements within the process of transition seems very reasonable. Indeed, this is exactly what the most successful of these transitional economies have done.

\section{Acknowledgments}

We wish to thank Daniel Berkowitz, William A. Brock, Richard H. Day, Dietrich Earnhart, Peter Flaschel, Shirley J. Gedeon, Roger Guesnerie, Cars H. Hommes, Michael Kopel, Mark Knell, Marji Lines, Robert McIntyre, Tönu Puu, John D. Sterman, E. Lynn Turgeon, Yuri V. Yakovets, and Wei-Bin Zhang for either useful materials or comments. None of these are responsible for any errors or questionable interpretations contained within this paper.

\section{References}

Aghion, P. and Blanchard, O.J. (1994). On the speed of transition in Central Europe. NBER Macroeconomics Annual 9, $283-320$.
Bauer, T. (1978). Investment cycles in planned economies. Acta Oeconomica 21, 243-260.

Brada, J.C. and King, A.E. (1992). Is there a j-curve for the economic transition from socialism to capitalism? Economics of Planning 25, 37-53.

Benedicks, M. and Carleson, L. (1991). The dynamics of the Hénon map. Annals of Mathematics 133, 73-169.

Brock, W.A. (1993). Pathways to randomness in the economy: Emergent nonlinearity and chaos in economics and finance. Estudios Economicos 8, 3-55.

Brock, W.A. and Hommes, C.H. (1997). Rational routes to randomness. Econometrica, in press [earlier draft available as SSRI Working Paper No. 9506, University of Wisconsin Madison].

Brock, W.A., Hsieh, D. and LeBaron, B. (1991). Nonlinear Dynamics, Chaos, and Instability. MIT Press, Cambridge, MA.

Calvo, G. and Corricelli, F. (1992). Stagflationary effects of stabilization programs in reforming socialist countries: Enterprise-side and household-side factors. World Bank Economic Review 6, 71-90.

Chiarella, C. (1988). The cobweb model: Its instability and the onset of chaos. Economic Modelling 5, 377-384.

Colander, D. (Ed.) (1996). Beyond Microfoundations: Post Walrasian Macroeconomics. Cambridge University Press, New York.

Day, R.H. and Huang, W. (1990). Bulls, bears, and market sheep. Journal of Economic Behavior and Organization 14, 299-329.

Day, R.H. and Walter, J.-L. (1989). Economic growth in the very long run: On the multiple phase interaction of population, technology, and social infrastructure. In Chaos, Sunspots, Bubbles, and Nonlinearity (W.A. Barnett, J. Geweke and K. Shell, Eds.). Cambridge University Press, Cambridge, UK, 253-289.

de Melo, M. and Gelb, A. (1996). A comparative analysis of twenty-eight transition economies in Europe and Asia. Post-Soviet Geography and Economics 37, 265-285.

Ellman, M. (1994). Transformation, depression, and economics: Some lessons. Journal of Comparative Economics 19, 1-21.

Ezekiel, M. (1938). The cobweb theorem. Quarterly Journal of Economics 52, 255-280.

Feldpausch, C.M. (1997). The political economy of chaos: multiple equilibria and fractal basin boundaries in a nonlinear environmental economy. Ph.D. Dissertation, American University, Washington, DC.

Fischer, S., Sahay, R. and Végh, C.A. (1996). Stabilization and growth in transition economies: The early experience. Journal of Economic Perspectives 10, 45-66.

Forrester, J.W. (1977). Growth cycles. De Economist 125, 525-543.

Goldmann, J. (1975). Makroekonomicka Analyzá a Prognozá [Macroeconomic Analysis and Prognosis]. Academia, Prague.

Goodwin, R.M. (1951). The nonlinear accelerator and the persistence of business cycles. Econometrica 19, 1-17.

Gottschalk, P. and Smeeding, T. (1997). International evidence on income distribution in modern economies: Where do we stand? In IEA Proceedings on Contemporary Economic Developments (M. Kayser and Y. Mundlak, Eds.). Oxford University Press, Oxford, forthcoming.

Grandmont, J.-M. (1994). Expectations formation and stability of large socioeconomic systems. CEPREMAP Working Paper No. 9424, Paris.

Guesnerie, R. (1993). Successes and failures in coordinating expectations. European Economic Review 37, 243-268. 
Hicks, J.R. (1950). A Contribution to the Theory of the Trade Cycle. Oxford University Press, London.

Hommes, C.H. (1991). Chaotic Dynamics in Economic Models: Some Simple Case Studies. Wolters-Noordhoff, Groningen.

Hommes, C.H. (1994). Dynamics of the cobweb model with adaptive expectations and nonlinear supply and demand. Journal of Economic Behavior and Organization 24, 315-335.

Hommes, C.H., Nusse, H.E. and Simonovits, A. (1995). Cycles and chaos in a socialist economy. Journal of Economic Dynamics and Control 19, 155-179.

Kac, M. (1968). Mathematical mechanisms of phase transitions. In Statistical Physics: Phase Transitions and Superfluidity, Vol. 1 (M. Chrétien, E. Gross and S. Deser, Eds.). Brandeis University Summer Institute in Theoretical Physics, 1966, pp. 241-305.

Kalecki, M. (1970). Theories of growth in different social systems. Scientia 40, 1-6.

Kamiński, B., Kwieciński, A. and Michalek, J.J. (1993). Competitiveness of the Polish economy in transition. PPRG Discussion Paper No. 20, Warsaw University.

Kornai, J. (1994). Transformational recession: The main causes. Journal of Comparative Economics 19, 39-63.

Laban, R. and Wolf, W.C. (1993). Large-scale privatization in transition economies. American Economic Review 83, $1199-1210$.

Lorenz, H.-W. (1992). Multiple attractors, complex basin boundaries, and transient motion. In Dynamic Economic Models and Optimal Control (G. Feichtinger, Ed.). NorthHolland, Amsterdam, pp. 411-430.

Lorenz, H.-W. (1993). Complex transient motion in continuous-time economic models. In Nonlinear Evolution of Spatial Economic Systems (P. Nijkamp and A. Reggiani, Eds.). Springer-Verlag, Heidelberg, pp. 112-137.

McDonald, S., Grebogi, C., Ott, E. and Yorke, J.A. (1985). Fractal basin boundaries. Physica D 17, 125-153.

Melitz, J. and Waysand, C. (1994). The role of government aid to firms during the transition to a market economy: Russia 1992-1994. Document de Travail No. 9435, CREST-INSÉE, Paris.

Mora, L. and Viana, M. (1993). Abundance of strange attractors. Acta Mathematica 171, 1-71.

Murrell, P. (1991). Can neoclassical economics underpin the reform of centrally planned economies? Journal of Economic Perspectives 5, 59-76.

Murrell, P. (1996). How far has the transition progressed? Journal of Economic Perspectives 10, 25-44.

Newhouse, S. (1974). Diffeomorphisms with infinitely many sinks. Topology 13, 9-18.

Palis, J. and Takens, F. (1993). Hyperbolicity and Sensitive Chaotic Dynamics at Homoclinic Bifurcations. Cambridge, University Press, Cambridge, UK

Palmer, R.G., Arthur, W.B., Holland, J.H., LeBaron, B. and Tayler, P. (1994). Artificial economic life: A simple model of a stockmarket. Physica D 75, 264-274.

Portes, R. (1994). Transformation traps. Economic Journal 104, 1178-1189.

Puu, T. (1990). A chaotic model of the business cycle. Occasional Paper Series on Socio-Spatial Dynamics 1, 1-19.

Puu, T. (1997). Nonlinear Economic Dynamics, 4th ed. SpringerVerlag, Heidelberg.

Rosser, J.B. Jr. (1991). From Catastrophe to Chaos: A General Theory of Economic Discontinuities. Kluwer Academic Publishers, Boston.

Rosser, J.B. Jr. and Rosser, M.V. (1994). Long wave chaos and systemic economic transformation. World Futures 39, 192-207.
Rosser, J.B. Jr. and Rosser, M.V. (1995). Chaotic hysteresis and systemic economic transformation. Mimeo, James Madison University.

Rosser, J.B. Jr. and Rosser, M.V. (1996a). Comparative Economics in a Transforming World Economy. Richarc. D. Irwin, Chicago

Rosser, J.B. Jr. and Rosser, M.V. (1996b). Macroeconomic collapse during systemic change. In Economics of Transition: Structural Adjustments and Growth Prospects in Eastern Europe (M. Knell, Ed.). Edward Elgar, Cheltenham, UK, pp. 70-86.

Rosser, J.B. Jr. and Rosser, M.V. (1996c). Endogenous chaotic dynamics in transitional economies. Chaos, Solitons \& Fractals 7, 2189-2197.

Rosser, J.B. Jr. and Rosser, M.V. (1997a). Schumpeterian evolutionary dynamics and the collapse of Soviet-bloc socialism. Review of Political Economy 9, 211-223.

Rosser, J.B. Jr. and Rosser, M.V. (1997b). Complex dynamics and systemic change: How things can go very wrong. Journal of Post Keynesian Economics 20, 103-122.

Rosser, M.V. (1993a). The external dimension of Soviet economic reform. Journal of Economic Issues 27, 813-824.

Rosser, M.V. (1993b). The pattern of external economic relations in the former Soviet Union and economic reform. International Journal of Social Economics 20, 43-53.

Samuelson, P.A. (1939). A synthesis of the principle of acceleration and the multiplier. Journal of Political Economy 47, 786-797.

Simonovits, A. (1991a). Investment limit cycles in a socialist economy. Economics of Planning 24, 27-46.

Simonovits, A. (1991b). Investments, starts, and cycles in socialist economies: A mathematical model. Journal of Comparative Economics 15, 460-475.

Smale, S. (1965). Diffeomorphisms with many periodic points In Differential and Combinatorial Topology (S.S. Cairns, Ed.). Princeton University Press, Princeton, 63-80.

Smale, S. (1967). Differentiable dynamical systems. Bulletin of the American Mathematical Society 73, 747-817.

Sorger, G. (1994). Boundedly rational chaos: An example of a self-fulfilling mistake. Mimeo, University of Vienna.

Sterman, J.D. (1985). A behavioral model of the long wave. Journal of Economic Behavior and Organization 6, 17-53.

Sterman, J.D. and Mosekilde, E. (1996). Business cycles and long waves: A behavioral disequilibrium perspective. In Business Cycles: Theory and Empirical Methods (W. Semmler, Ed.). Kluwer Academic Publishers, Boston, 13-52.

Stiglitz, J.E. (1994). Whither Socialism? MIT Press, Cambridge, MA

Tamborski, M. (1995). Efficiency of new financial markets: The case of Warsaw stock exchange. IRES Discussion Paper No. 9504, Université Catholique de Louvain.

Uhlig, H. (1993). Transition and financial collapse. Working Paper No. 40, Center for Economic Studies, University of Munich.

Yavlinsky, G. and Braguinsky, S. (1994). The inefficiency of laissez-faire in Russia: Hysteresis effects and the need for policy-led transformation. Journal of Comparative Economics 19, 88-116.

Yorke, J.A. and Alligood, K.T. (1983). Cascades of perioddoubling bifurcations: A prerequisite for horseshoes. Bulletin of the American Mathematical Society 89, 319-322.

Zou, H.-F. (1991). Socialist economic growth and political investment cycles. European Journal of Political Economy 7, $141-157$. 


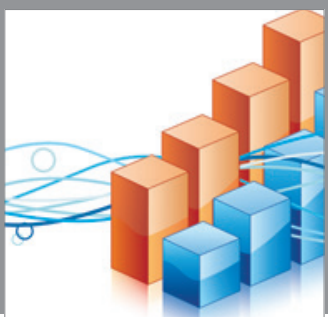

Advances in

Operations Research

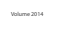

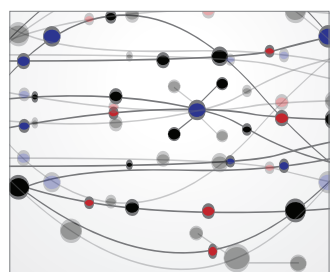

\section{The Scientific} World Journal
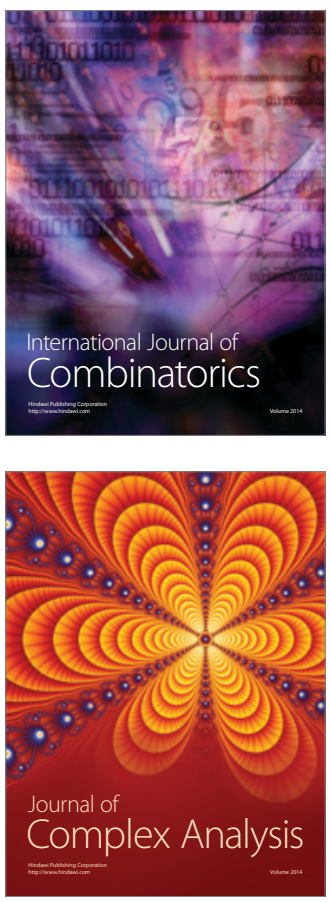

International Journal of

Mathematics and

Mathematical

Sciences
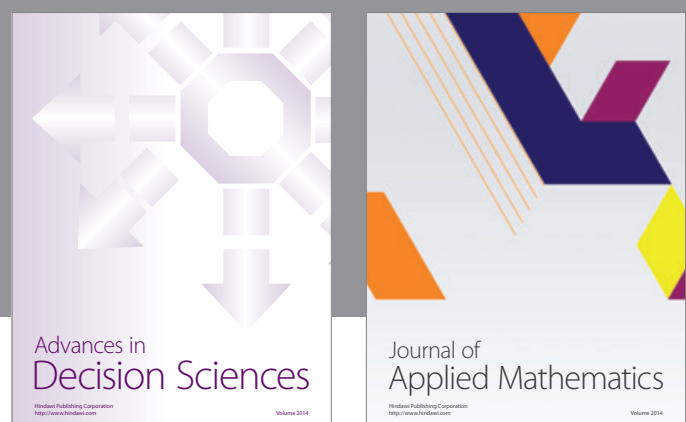

Journal of

Applied Mathematics
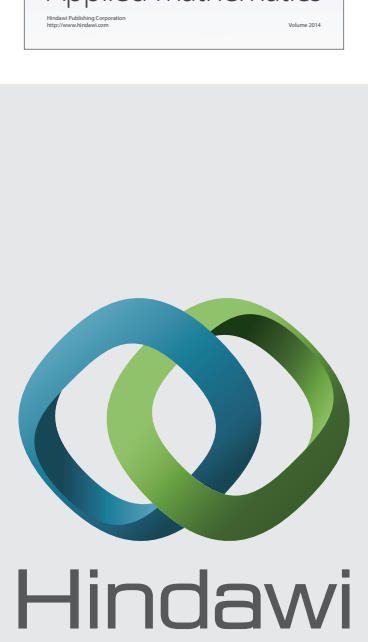

Submit your manuscripts at http://www.hindawi.com
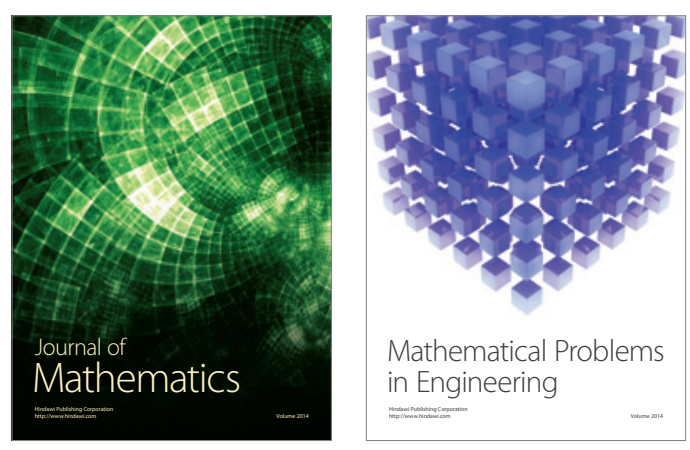

Mathematical Problems in Engineering
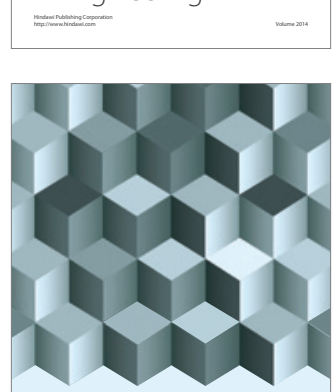

Journal of

Function Spaces
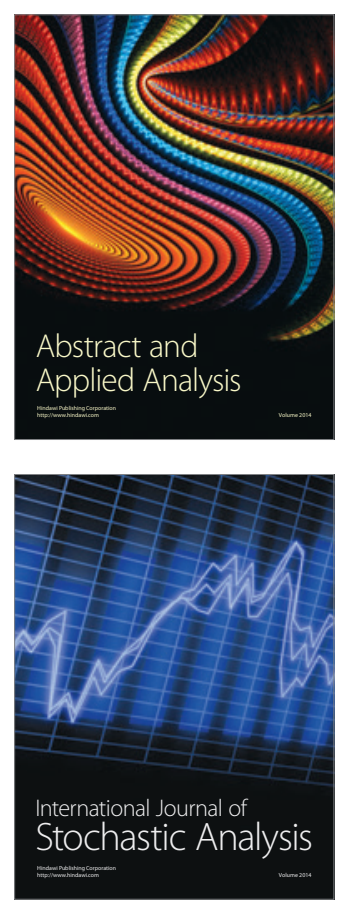

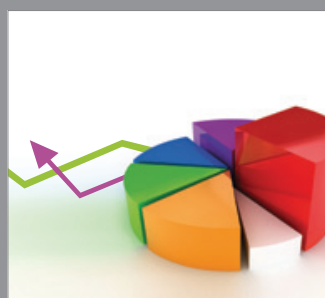

ournal of

Probability and Statistics

Promensencen
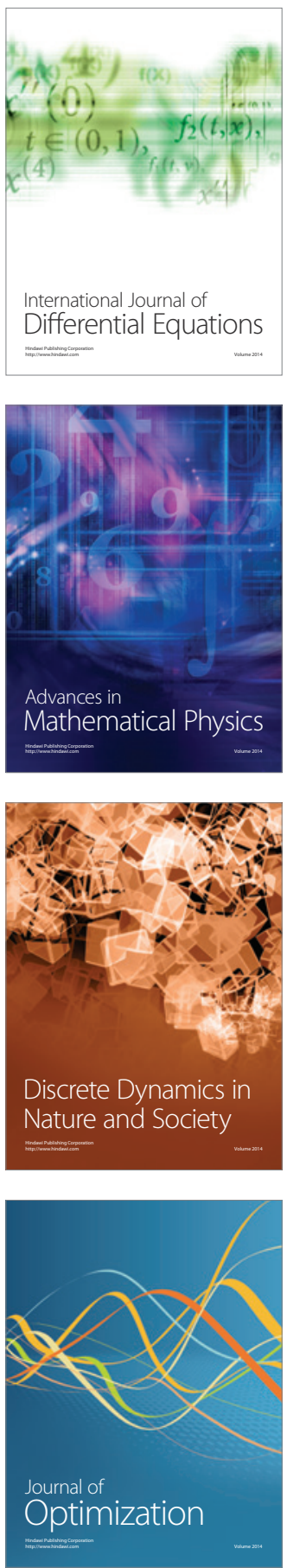